\title{
Influence of Longitudinal Bar Corrosion on Shear Behavior of RC Beams
}

\author{
Xin Xue ${ }^{1}$ and Hiroshi Seki ${ }^{2}$
}

Received 3 March 2010, accepted 18 April 2010

\begin{abstract}
There have been few reports on the shear behavior of reinforced concrete (RC) beams with corroded longitudinal bars, and the influence of longitudinal bar corrosion has yet to be quantified. Given this background, experimental investigations were conducted to investigate the shear behavior of RC beams with corroded longitudinal bars, in which parameters such as corrosion level and shear-span-to-effective-depth-ratio were taken into consideration. Analytical investigations were also performed to evaluate the load-carrying mechanism of these specimens. The investigational results indicate that the shear behavior of RC beams is influenced not only by the corrosion level of the longitudinal bars but also by the shear-span-to-effective-depth-ratio (a/d). Based on these experimental results, a modified equation capable of calculating the shear capacity of RC beams with corroded longitudinal bars was proposed and its validity was proved.
\end{abstract}

\section{Introduction}

Unlike flexural failures, reinforced concrete shear failures are relatively brittle and, particularly for members without stirrups, can occur without warning. If $\mathrm{RC}$ members are placed in corrosion environments, the performance of composite materials such as concrete and reinforcement will deteriorate. Corrosion of embedded reinforcement is one of the most critical consequences of aging RC members subjected to chloride-induced corrosion damage and concrete carbonation. To prevent these $\mathrm{RC}$ members from shear failure, there is a need to develop a tool that can evaluate and predict the shear behavior during their service life. The current JSCE code shear equation (JSCE, 2007), however, is based on a large number of experimental results, in which cases of corroded reinforcements are not take into account. Therefore, the shear capacity of RC members with corroded reinforcement cannot be accurately evaluated using the current shear equation.

The shear behavior of RC beams with corroded longitudinal bars has not been widely studied. As longitudinal bars corrode, apart from cross-section loss, it will also result in such effects as deterioration in bond strength and generation of corrosion cracks in concrete which caused by the accumulation and the expansion of the corroded product. Because cross-section loss can generally be considered just an influence on flexural behavior, published studies have mainly focused on the latter two effects. It is agreed that the latter two effects may result in a decrease in stiffness of RC beams due to

\footnotetext{
${ }^{1}$ Assistant researcher, Department of Civil and Environmental Engineering, School of creative Science and Engineering, Waseda University, Japan.

E-mail: cnxuexinjp@gmail.com

${ }^{2}$ Professor, Department of Civil and Environmental Engineering, School of creative Science and Engineering Waseda University, Japan.
}

the deterioration in tension-stiffness effects and the deficit in integrity of concrete (Sahamitmongkol et al. 2008; Sato et al. 2003; Matsuo et al. 2004; Hashimoto et al. 2003). Furthermore, several studies have suggested that the deterioration in bond strength might result in the transition of load-carrying mechanism, and thus cause a change in load capacity (Sato et al. 2003; Matsuo et al. 2004; Hashimoto et al. 2003). However, there is a lack of theoretical explanation, and the influence of longitudinal bar corrosion has not been quantified.

Shear span is generally thought to play a very important role in the shear behavior of RC beams. Most of the previous studies concerning corroded RC beams, however, have focused on the corrosion level of the longitudinal bars, while ignoring the influence of shear span. To inquire into the shear behavior of RC beams with corroded longitudinal bars and, furthermore, to quantify the influence of longitudinal bar corrosion, systematical investigations taking into account all potentially influential parameters should be carried out.

Given the above mentioned background, this paper inquired into the shear behavior of RC beams with corroded longitudinal bars through experimental and analytical investigations and made efforts to propose an equation capable of predicting the shear capacity of corroded $\mathrm{RC}$ beams.

\section{Shear load carrying mechanism of sound $\mathrm{RC}$ beams}

The loads applied to RC beams are supposed to be sustained either by the change in tensile force $\mathrm{T}$, which is called the beam mechanism, or by the change in the length of the internal lever $\operatorname{arm} Z$, which is called the tie-arch mechanism (see Eq. 1 and Fig. 1) (Fenwick and Paulay 1968). In the beam mechanism, the perfect bond effect is indispensable in transferring the tensile stress arising in the longitudinal bars to the concrete, which causes diagonal cracks within the shear span. After di- 
agonal cracks initiate, the shear force is known to be carried by three parts: the shear resistance by the concrete in the compression zone, the shear resistance by the aggregate interlock action along the crack surface, and the shear resistance by the dowel action of the longitudinal bars (Tanabe et al. 2000). The beams will fail in diagonal tension and their shear capacity can be calculated by Eq. 2 (Niwa 1983). In the tie-arch mechanism, an inclined strut going from the loading point to the support is formed (see Fig. 1). The shear capacity is determined by the compression concrete zone and can be calculated by Eq. 3 (Niwa et al. 1986). The Eq. 2 and Eq. 3 are basic version of current JSCE code shear equation, and it has been confirmed that these equations can predict shear capacity accurately.

For beams with short shear span, the loads are generally sustained by both mechanisms at first. After diagonal cracks initiate, the beam mechanism collapses and the remaining tie-arch mechanism continues to sustain the larger shear load. Finally, due to the crush of concrete in the compression zone the beam fails in shear compression. For beams with long shear span, the distance between the loading point and the support weakens the tie-arch mechanism, and the beam mechanism plays a more important role in load-carrying work. After the beam mechanism collapses, the rapid propagation of diagonal cracks and the abrupt breakdown of aggregate interlock action trigger diagonal tension failure. At this point, the remaining tie-arch mechanism can no longer carry the shear load.

$$
\begin{aligned}
Q & =\frac{d M}{d x}=\frac{d(T \cdot Z)}{d x} \\
& =\frac{d T}{d x} \cdot Z+T \cdot \frac{d Z}{d x} \\
V_{c} & =0.2 f_{c}^{\prime 1 / 3}\left(100 p_{t}\right)^{1 / 3}\left(\frac{10^{3}}{d}\right)^{1 / 4}\left(0.75+\frac{1.4 d}{a}\right) b_{w} d \\
V_{c} & =\frac{0.24 f_{c}^{\prime 2 / 3}\left(1+\sqrt{100 p_{t}}\right)(1+3.33 r / d)}{1+(a / d)^{2}} b_{w} d
\end{aligned}
$$

Where $f_{c}^{\prime}$ is compression strength of concrete in $\mathrm{N} / \mathrm{mm}^{2}$, $p_{t}$ is steel ratio of longitudinal bars represent by percentage, $b_{w}$ and $d$, are the width and effective depth of beam section respectively in $\mathrm{mm}, r$ is the width of loading plate in $\mathrm{mm}$.

\section{Outline of experiment}

\subsection{Specimen details}

The geometry and reinforcement arrangement of the specimens are shown in Fig. 2. The specimens had the same cross section of $120 \mathrm{~mm}$ in width, $240 \mathrm{~mm}$ in overall height, and $220 \mathrm{~mm}$ in effective depth. The specimens had three types of length to take into consideration the influence of shear span. Ultra-high strength steel bars D19 (Specific : USD685A, $f_{y}=706 \mathrm{~N} / \mathrm{mm}^{2}$ ) were used as longitudinal bars to acquire strong flexural strength. The steel ratio was designed as $1.9 \%$, which is similar to that of conventional beams. To prevent the specimens from anchorage failure, the longitudinal bars were fixed to the steel plates placed outside the specimens using nuts.

The properties of specimens are summarized in Table 1. The experimental parameters were shear-span-toeffective-depth-ratio $(a / d)$ and corrosion level of the longitudinal bars. Apart from the specimens with an a/d of 2.6, which was thought to be sensitive to failure mode, specimens with four other different a/d $(1.5 \sim 4.0)$ were also fabricated. The specimens can be grouped into several series with the same $a / d$, each series containing one sound specimen and two or three corroded specimens with different corrosion levels. For example, the B (2.6)-m series represented a group of specimens with an $\mathrm{a} / \mathrm{d}$ of 2.6, and involved one sound specimen $\mathrm{B}(2.6)-\mathrm{m}$ and three corroded specimens $B(2.6)-\mathrm{m} 1 \sim \mathrm{m} 3$. Since severe corrosion would result in anchorage failure due to the dramatic decrease in bond strength, which is beyond the scope of this paper, the maximum percent average mass loss (to be specified later) used to describe the corrosion level, was set as $20 \%$. The Concrete mix proportions are specified in Table 2. The maximum size of coarse aggregate was $15 \mathrm{~mm}$. After casting, the speci-

Table 1 Properties of specimens.

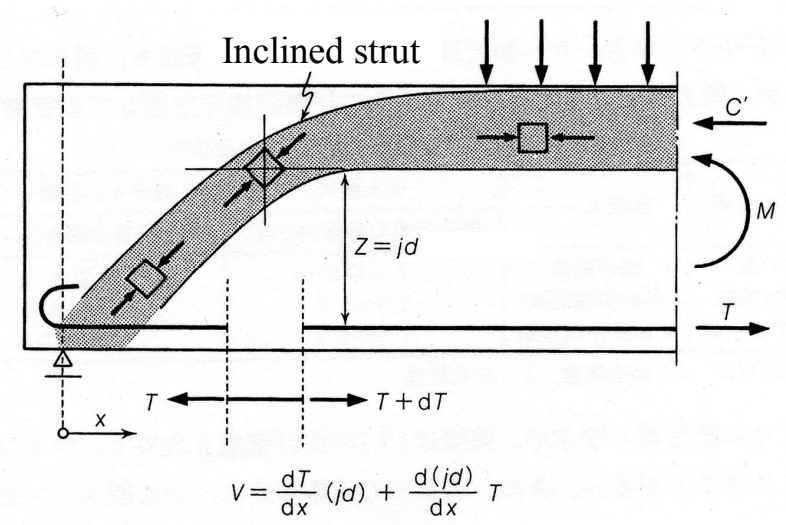

Fig. 1 Shear load-carrying mechanism.

\begin{tabular}{|c|c|c|}
\hline Specimen & $\mathrm{a} / \mathrm{d}$ & Condition of longitudinal bars \\
\hline $\mathrm{B}(1.5)-\mathrm{m}$ & 1.5 & Sound, Levels1 3 \\
\hline $\mathrm{B}(2.0)-\mathrm{m}$ & 2.0 & Sound, Levels1 2 \\
\hline $\mathrm{B}(2.6)-\mathrm{m}$ & 2.6 & Sound, Levels1 3 \\
\hline $\mathrm{B}(3.5)-\mathrm{m}$ & 3.5 & Sound, Levels1 2 \\
\hline $\mathrm{B}(4.0)-\mathrm{m}$ & 4.0 & Sound, Levels1 2 \\
\hline
\end{tabular}

Table 2 Mix proportions of concrete.

\begin{tabular}{|c|c|c|c|c|c|c|}
\hline \multirow{2}{*}{ W/C } & \multirow{2}{*}{$\mathrm{s} / \mathrm{a}$} & \multicolumn{5}{|c|}{ Unit quantity $\left(\mathrm{kg} / \mathrm{m}^{3}\right)$} \\
\cline { 3 - 7 } & & $\mathrm{C}$ & $\mathrm{W}$ & $\mathrm{S}$ & $\mathrm{G}$ & Ad. \\
\hline 0.48 & 0.52 & 387 & 186 & 881 & 842 & 5.8 \\
\hline
\end{tabular}




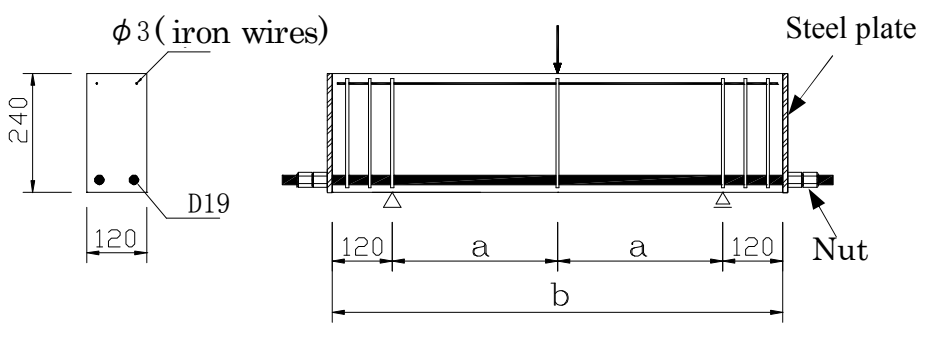

\begin{tabular}{|l|c|c|}
\hline Series & $\begin{array}{c}\mathrm{a} \\
(\mathrm{mm})\end{array}$ & $\begin{array}{c}\mathrm{b} \\
(\mathrm{mm})\end{array}$ \\
\hline $\mathrm{B}(1.5)-\mathrm{m}$ & 330 & 900 \\
\hline $\mathrm{B}(2.0)-\mathrm{m}$ & 440 & 1120 \\
\hline $\mathrm{B}(2.6)-\mathrm{m}$ & 580 & 1400 \\
\hline $\mathrm{B}(3.5)-\mathrm{m}$ & 770 & 1780 \\
\hline $\mathrm{B}(4.0)-\mathrm{m}$ & 880 & 2000 \\
\hline
\end{tabular}

Fig. 2 Specimen details.

mens were wet-cured for a period of 7 days, and then dry-cured for a period of at least 28 days.

\subsection{Corrosion method and valuation index}

The electrochemical corrosion tests details are shown in Fig. 3. The specimens were immersed in $3 \% \mathrm{NaCl}$ solution and the longitudinal bars and the copper plate placed outside the specimens were connected to the anode and cathode of a constant current generator respectively. A current density of $1 \mathrm{~mA} / \mathrm{cm}^{2}$ was imposed through the longitudinal bars. The amount time of the corrosion test, which could be determined using Faraday's Law, was controlled to vary the state of corrosion.

After load tests specimens were demolished, and the longitudinal bars were taken out to investigate the corrosion state. To facilitate the investigation, the longitudinal bars were cut into a manageable number of pieces. The corrosion products were roughly removed using a sand blast. The pieces were then immersed in a $10 \%$ ammonium hydrogen citrate solution for 24 hours for thorough cleaning. Since it was the average bond behavior along the whole longitudinal bars that was supposed to influence the shear behavior of $\mathrm{RC}$ beams (Yamamoto et al. 2005), percent average mass loss $\mathrm{C}$ was used to describe the corrosion state, which can be described as follows:

$$
C=\frac{\Delta w}{w} \times 100
$$

Where $\Delta \mathrm{w}$ is the average mass loss of corrosion bars, and $\mathrm{W}$ is the mass of original bars.

\subsection{Load test}

The specimens were subjected to load tests under simply supported conditions, as shown in Fig. 4. The load was applied to the middle span with a displacement increment of $0.2 \mathrm{~mm} / \mathrm{minute}$. Application of the load was monitored using a load cell, and the deflection at the mid-span was measured using displacement transducers placed under the specimens.

\section{Experimental results}

The experimental results are summarized in Table $\mathbf{3}$, in which the compression strength of concrete $f_{c}$, , percent

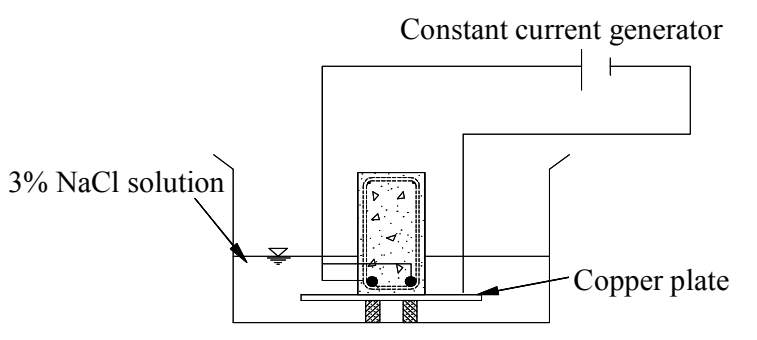

Fig. 3 Electrochemical corrosion tests details.

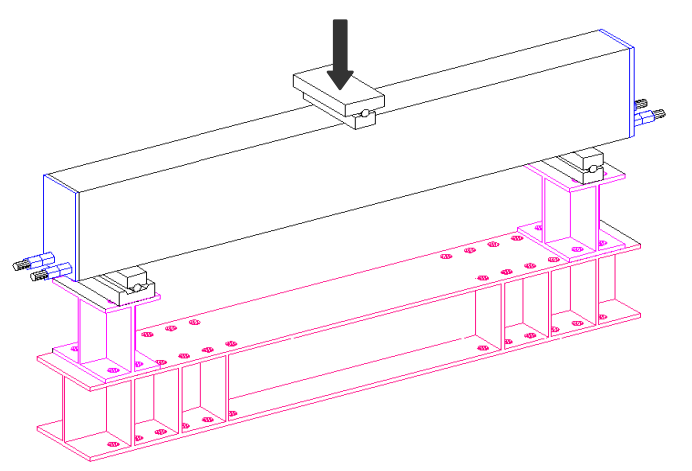

Fig. 4 Load test details.

average mass loss $C$, and the shear behavior such as failure load $P_{\text {test }}$ and failure mode were specified. The specimens were divided into three groups to describe their experimental results respectively:

Specimens with short shear span $\quad \mathrm{a} / \mathrm{d}=1.5$

Specimens with moderate shear span $\mathrm{a} / \mathrm{d}=2.0,2.6$

Specimens with long shear span $\quad \mathrm{a} / \mathrm{d}=3.5,4.0$

\subsection{Corrosion test results}

Rust stains along the longitudinal bars were observed on the surface in all specimens, as shown in Fig. 5. In the specimens whose percent average mass loss was above $10 \%$, cracks with a width over $1 \mathrm{~mm}$ were confirmed along the longitudinal bars. These cracks were thought to be induced by the expansion of the corroded products. Regarding the corrosion state of the longitudinal bars, severely corroded locations were confirmed at various points along the bars. 
Table 3 Experimental results.

\begin{tabular}{|c|c|c|c|c|}
\hline Specimens & $\begin{array}{c}f_{c}^{\prime} \\
(\mathrm{N} / \mathrm{mm} 2)\end{array}$ & $\begin{array}{c}C \\
(\%)\end{array}$ & $\begin{array}{l}P_{\text {test }} \\
(\mathrm{kN})\end{array}$ & Failure mode \\
\hline $\mathrm{B}(1.5)-\mathrm{m}$ & 36.0 & 0.0 & 199.4 & Splitting \\
\hline $\mathrm{B}(1.5)-\mathrm{m} 1$ & 35.1 & 2.7 & 200.6 & \multirow{3}{*}{ Splitting } \\
\hline $\mathrm{B}(1.5)-\mathrm{m} 2$ & 36.8 & 6.7 & 195.9 & \\
\hline $\mathrm{B}(1.5)-\mathrm{m} 3$ & 36.8 & 10.4 & 200.8 & \\
\hline $\mathrm{B}(2.0)-\mathrm{m}$ & 43.0 & 0.0 & 123.8 & \multirow{2}{*}{ Shear compress } \\
\hline $\mathrm{B}(2.0)-\mathrm{m} 1$ & 46.4 & 3.8 & 183.6 & \\
\hline $\mathrm{B}(2.0)-\mathrm{m} 2$ & 44.7 & 15.0 & 191.6 & Support flexure \\
\hline $\mathrm{B}(2.6)-\mathrm{m}$ & 33.1 & 0.0 & 86.4 & Diagonal tension \\
\hline $\mathrm{B}(2.6)-\mathrm{m} 1$ & 35.1 & 7.0 & 101.4 & \multirow{2}{*}{ Shear compress } \\
\hline $\mathrm{B}(2.6)-\mathrm{m} 2$ & 36.2 & 13.9 & 124.9 & \\
\hline $\mathrm{B}(2.6)-\mathrm{m} 3$ & 36.2 & 17.0 & 111.0 & Support flexure \\
\hline $\mathrm{B}(3.5)-\mathrm{m}$ & 43.0 & 0.0 & 79.7 & Diagonal tension \\
\hline $\mathrm{B}(3.5)-\mathrm{m} 1$ & 45.8 & 5.4 & 78.8 & \multirow{2}{*}{ Bond splitting } \\
\hline $\mathrm{B}(3.5)-\mathrm{m} 2$ & 44.7 & 7.3 & 61.9 & \\
\hline $\mathrm{B}(4.0)-\mathrm{m}$ & 35.2 & 0.0 & 66.8 & Diagonal tension \\
\hline $\mathrm{B}(4.0)-\mathrm{m} 1$ & 34.7 & 3.7 & 60.3 & Bond compress \\
\hline $\mathrm{B}(4.0)-\mathrm{m} 2$ & 33.7 & 4.9 & 53.7 & Bond splitting \\
\hline
\end{tabular}

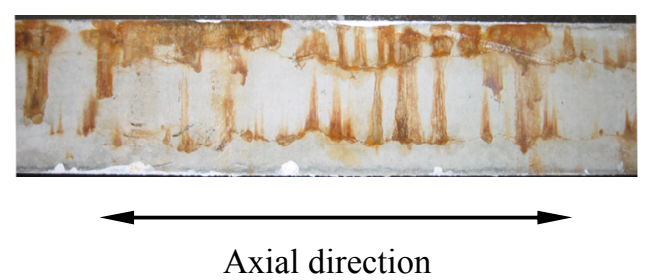

Fig. 5 Corrosion state on bottom face.

\subsection{Load test results}

(1) Specimens with short shear span $(a / d=1.5)$

Experimental results of the B (1.5)-m series are summarized in Fig. 6. Regarding load-displacement relationship, compared to the sound specimen B (1.5)-m, the corroded specimens exhibited a slight decrease in post-diagonal-crack stiffness, but no change in shear capacity. Crack pattern at failure is shown in Fig. 6(b), in which a critical crack which caused the failure of the specimen is highlighted. Even though the crack pattern varied with the corrosion level, all the specimens failed in the same brittle manner: after the diagonal crack initiated at mid-depth of the section within the shear span, it propagated toward the loading point and the support, and ultimately the critical diagonal crack penetrated the section, causing a splitting failure from the loading point to the support (see photo in Fig. 6(b)). The same failure mode and nearly the same shear capacity implied that the longitudinal bar corrosion had little influence on shear behavior. This can be explained by the load-carrying mechanism shown in Fig. 6(b). In beams with short shear

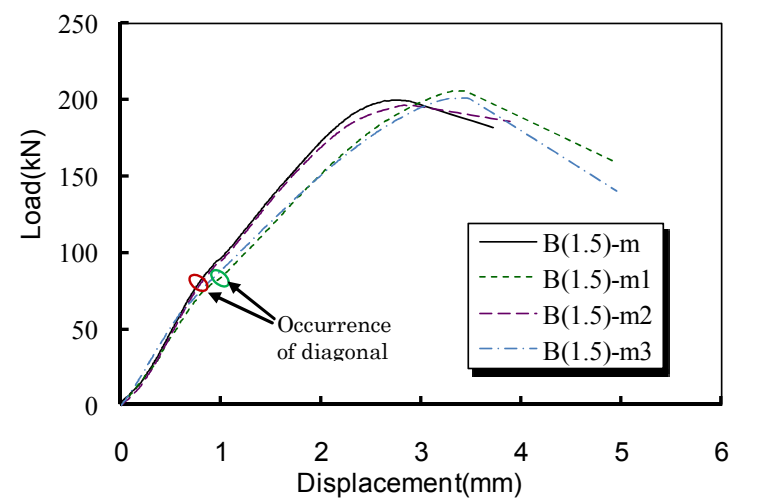

(a) Load-displacement relationship

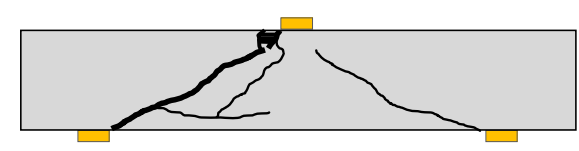

B(1.5)-m

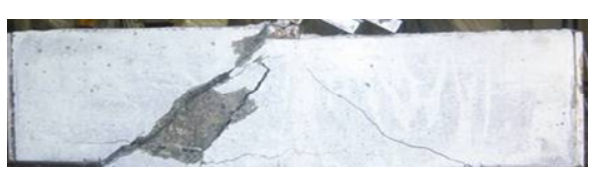

$\underline{B(1.5)-m ~(p h o t o) ~}$

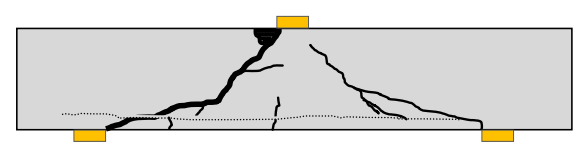

$\underline{B(1.5)-m 3}$

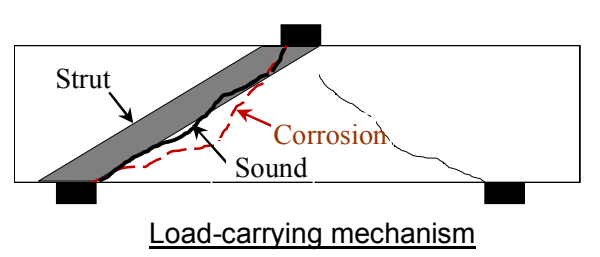

(b) Crack pattern at failure and load-carrying mechanism

Fig. 6 Load test results of $B(1.5)-m$ series.

span, load is thought to be sustained by the inclined compression strut from the loading point to the support (Kosa et al. 2007). As the longitudinal bars corroded, the deterioration in bond effects might cause the shift of the diagonal cracks toward the loading point. However, this did not affect the compression strut by which the load capacity is determined.

\section{(2) Specimens with moderate shear $\operatorname{span}(a / d=2.0$, 2.6)}

Two main conventional failure modes were observed during the load tests. One is diagonal tension failure caused by a type of concrete splitting along one critical 
diagonal crack, and another is shear compression failure due to the crush of concrete near the loading point.

Figure 7 shows the load test results of the B(2.0)-m series. Both the sound specimen $\mathrm{B}(2.0)-\mathrm{m}$ and the corroded specimen $\mathrm{B}(2.0)-\mathrm{m} 1$ failed in shear compression, whereas $\mathrm{B}(2.0)-\mathrm{m} 2$, whose longitudinal bars were severely corroded, failed in a splitting mode shown in Fig. 7(b). In specimen $\mathrm{B}(2.0)-\mathrm{m} 2$, due to the dramatic decrease in bond strength, the tensile force arising in the longitudinal bars was transferred to the support and caused eccentric loads acting on the side plane. These eccentric loads generated a bending at the support and induced the initiation of flexure cracks at the upside surface. When these flexural cracks joined with the cracks propagated upward from the support, the speci-

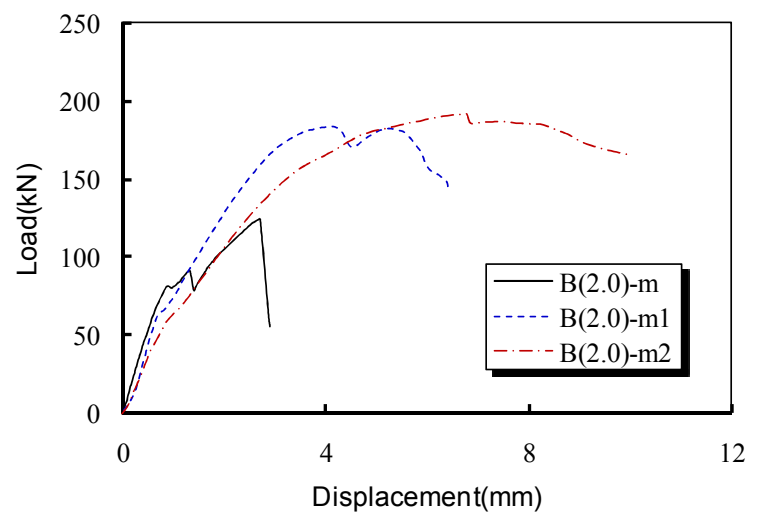

(a) Load-displacement relationship

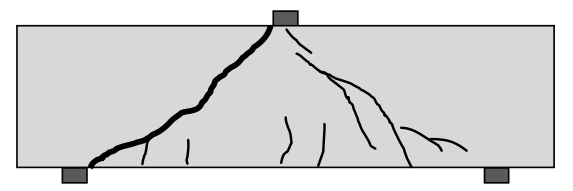

$\underline{B(2.0)-m}$

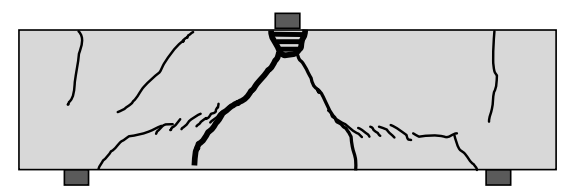

$\underline{\mathrm{B}(2.0)-\mathrm{m} 1}$

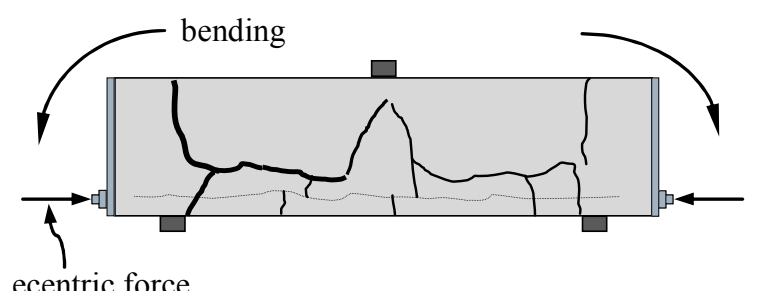

$\underline{B(2.0)-m 2}$

(b) Crack pattern at failure

Fig. 7 Load test results $(a / d=2.0)$. men lost its load-carrying ability. In this paper, this type of failure mode is called "support flexure failure".

Regarding the crack pattern at failure shown in Fig. 7(b), as the longitudinal bars corroded, the critical diagonal crack shifted toward the load point with steeper inclination, and the concrete area above the critical diagonal crack became larger. Figure 7(a) shows the load-displacement relationship. It can be seen that post-diagonal-crack stiffness decreased and shear capacity increased gradually as the corrosion level increased. The decrease in stiffness is thought to be caused by the deterioration of tension-stiffness due to longitudinal bar corrosion. The increase in the shear capacity can be attributed to the enlargement of the concrete compression area in the corroded specimens, which im-

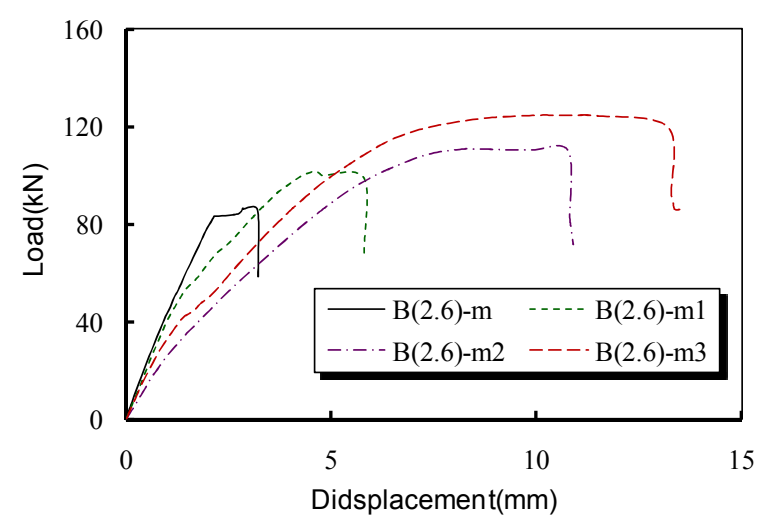

(a) Load-displacement relationship
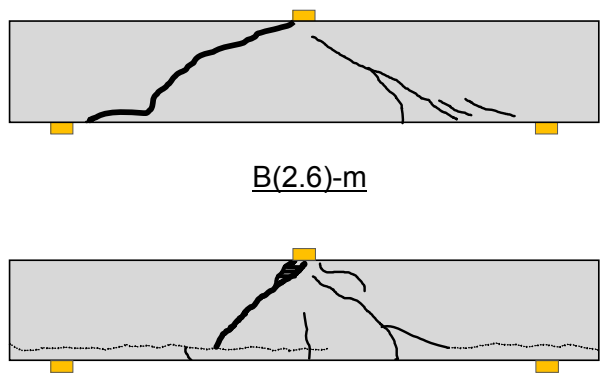

$\underline{B(2.6)-m 1}$

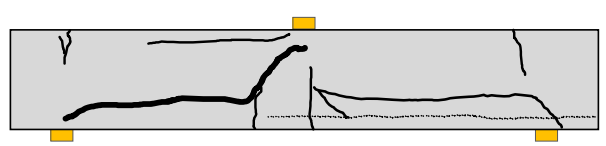

$\underline{B(2.6)-m 2}$

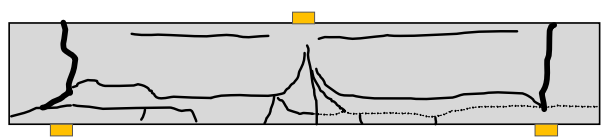

$\underline{B(2.6)-\mathrm{m} 3}$

(b) Crack pattern at ultimate

Fig. 8 Load test results $(a / d=2 \cdot 6)$. 
plies the buildup of the tie-arch mechanism.

Figure 8 shows the load test results of the B(2.6)-m series. The failure mode varied with the corrosion level of the longitudinal bars. The sound specimen $\mathrm{B}(2.6)-\mathrm{m}$ failed in diagonal tension. The corroded specimens $\mathrm{B}(2.6)-\mathrm{m} 1$ and $\mathrm{B}(2.6)-\mathrm{m} 2$ failed in shear compression, and $\mathrm{B}(2.6)-\mathrm{m} 3$ failed in support flexure.

The load-displacement relationship is shown in Fig. 8(a), which exhibits a noticeable decrease in the post-diagonal-crack stiffness and a significant increase in shear capacity as the corrosion level increased. Figure $\mathbf{8}(\mathbf{b})$ shows the crack pattern at failure. As the corrosion level increased, the diagonal cracks shifted gradually toward the loading point.

In the sound specimen, an a/d of 2.6 is the critical point that determines whether or not the remaining tie-arch mechanism can sustain any more shear load after the beam mechanism collapses, which is apt to result in different failure modes. Since the remaining tie-arch mechanism could no longer carry the shear load, the sound specimen B (2.6)-m failed in diagonal tension failure. In the corroded specimens B (2.6)-m1 and B (2.6)- $\mathrm{m} 2$, due to the deterioration in bond strength, the tensile force arising in the longitudinal bars was transferred to the support and caused a buildup in the remaining tie-arch mechanism. Therefore, the specimens could sustain a larger shear load and failed in shear compression. In B (2.6)-m3, further deterioration in bond strength transferred larger tensile force to the support and resulted in support failure, which has been described in the results of B (2.0)-m2.

(3) Specimens with long shear span (a/d=3.5, 4.0) Because B (3.5)-m series share similarities with B (4.0)- $\mathrm{m}$ series in the shear behavior, only the experimental results of the $\mathrm{B}(4.0)-\mathrm{m}$ series are discussed here. The results are shown in Fig. 9. Compared to the sound specimen, the diagonal cracks in corroded specimens shifted slightly toward the loading point (see Fig. 9(b)). The sound specimen B (4.0)-m failed in diagonal tension and the corroded specimens exhibited different failure modes. In the corroded specimens, as the applying load increased, the diagonal cracks, which initiated in the mid-depth of the section within the shear span, propagated toward the loading point and the support, and developed into horizontal bond cracks along the longitudinal bar. Regarding the B (4.0)-m1, the development of these bond cracks reduced the stiffness of specimens and caused a concentration of deformation at the middle span, which resulted in the premature crush of concrete near the loading point (see Fig. 9(b)). As for the B (4.0)-m2, these bond cracks and the diagonal cracks propagated rapidly toward the support and the loading point respectively, and ultimately they penetrated the section and caused a concrete splitting failure (see Fig. 9(b)). Since the development of these bond cracks played a very important role in shear behavior, in this paper, the failure mode of B (4.0)-m1 and B (4.0)-m2 are called "bond

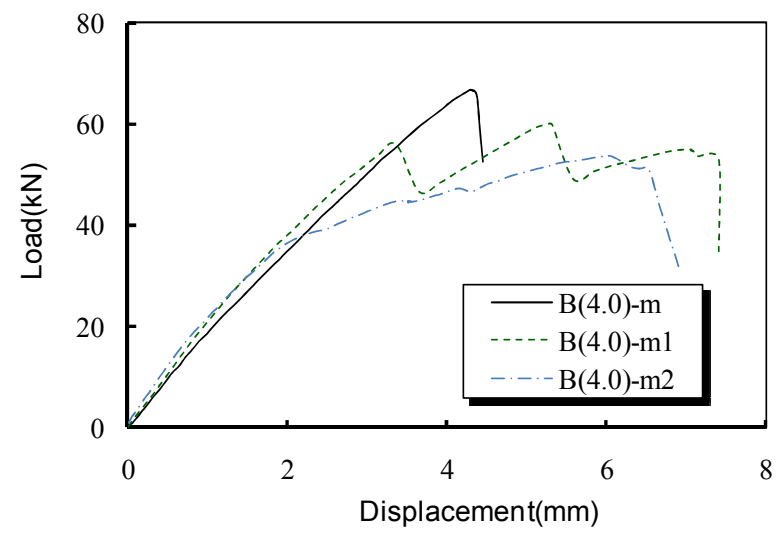

(a) Load-displacement relationship
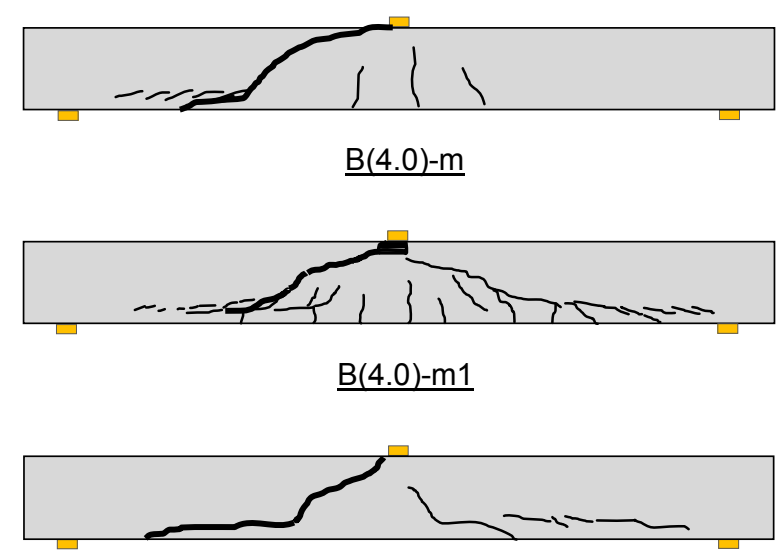

$\underline{B(4.0)-m 2}$

(b) Crack pattern at failure

Fig. 9 Load test results $(\mathrm{a} / \mathrm{d}=4.0)$.

compress failure" and "bond splitting failure" respectively.

Load-displacement relationship is shown in Fig. 9(a). Compared to the sound specimen B (4.0)-m, the sustainable load of the corroded specimens once dropped and then increased again during the load test, but finally failed with a relatively lower load. The drop in the sustainable load could be attributed to the rapid propagation of the bond cracks. In corroded specimens, the deterioration in bond strength weakened the beam mechanism, but even though the tensile force was transferred to the support the tie-arch mechanism could not be sustained due to the development of bond cracks and the long distance between the loading point and support. As a result, after the beam mechanism collapsed, the specimens could no longer carry the loads. This reveals that the corrosion of the longitudinal bars may have adverse influence on shear capacity when the shear span became longer. 


\section{Analytical investigation}

\subsection{Outline of analysis}

(1) Analytical model

A two-dimensional nonlinear analysis was conducted in this paper. The analytical model is shown in Fig. 10. Because of the symmetry, the left side of the specimen was chosen for analysis and the middle cross-sectional plan was confined in the $\mathrm{x}$ direction. To prevent areas near the loading point and support from local failure, elastic elements with strong stiffness was adopted in the model. The concrete matrixes and the longitudinal bars were modeled using iso-parametric elements and truss elements respectively, and interface elements were introduced in between to model the bond effects. Taking into consideration of the full anchorage of longitudinal bars in the experimental specimens, the longitudinal bar elements outside the support were modeled as perfect bond to the concrete elements. The mesh size was determined in accordance with the maximum coarse aggregate. Modified Newton-Raphson method was used in iteration procedure and convergence is judged by energy norm. A smeared crack model was adopted to simulate the crack occurring in the concrete.

\section{(2) Constitutive law}

The stress-strain behavior of concrete is shown in Fig. 11(a). In the compression zone, the stress increases following a parabolic curve before it reaches compression strength, and then decreases linearly as strain progresses. In the tension zone, the stress increases linearly before it reaches tension strength, and then decreases following a tension softening model proposed by Hordijk (Hordijk 1991). To reduce the influence of mesh division, the parameters of fracture energy $G_{f}$ and $G_{c}$ were introduced in the tension and compression zones respectively to decide ultimate strain.

For the longitudinal bars, the yield condition of Von Mises without consideration of strain hardening was adopted. The stress-strain relationship is shown in Fig. 11(b). Regarding the bond behavior between the longitudinal bars and the concrete, a $\tau$-s relationship proposed by Dörr (1980) was adopted, which shows a limit in shear strength if the slip is larger than a certain value (see Fig. 11(c)).

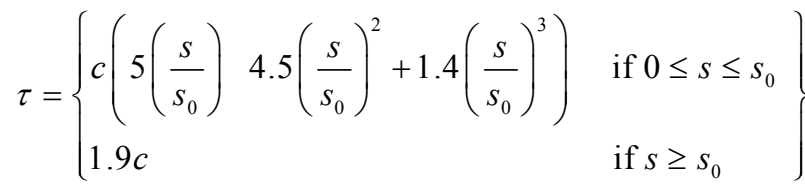

where $c=f_{t} \quad, \quad s_{0}=0.06 \mathrm{~mm}$

where $f_{t}$ is tensile strength of concrete

In the corroded specimens, the influence of longitudinal bar corrosion on bar mechanical properties and the bond behavior between bars and concrete was modeled. The young's modulus and the yield strength of corroded longitudinal bars were reduced using the following equation (JSCE 2006), given that there was no change in the cross-section (see Fig. 11(b)).

$$
\begin{aligned}
& f_{y} / f_{y o}=1.00-2.17 \times C / 100 \\
& E_{s} / E_{s o}=1.00-1.13 \times C / 100
\end{aligned}
$$

Where $f_{y}$ and $E_{s}$ are the yield strength and the young's modulus of corroded longitudinal bars, $f_{y o}$ and $E_{s o}$ are those of sound longitudinal bars.

Regarding the bond behavior of corroded longitudinal bars, the whole bond stress was reduced using the following equation (JSCE 2006).

$$
\tau_{b} / \tau_{b o}=\exp (-0.0607 \times C)
$$

Where $\tau_{b}$ is the bond stress of corroded longitudinal bars, $\tau_{b o}$ is the bond stress of sound longitudinal bars.

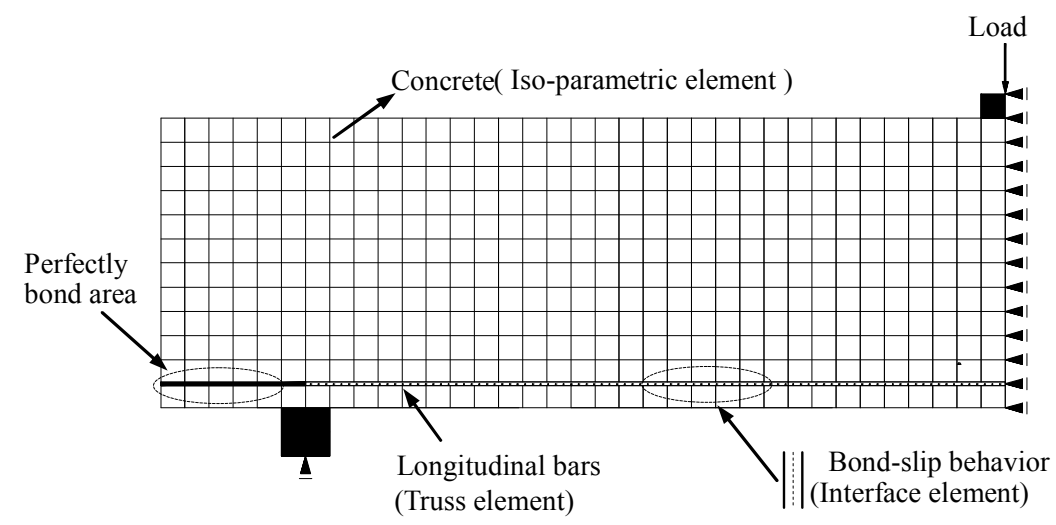

Fig. 10 Analytical model. 


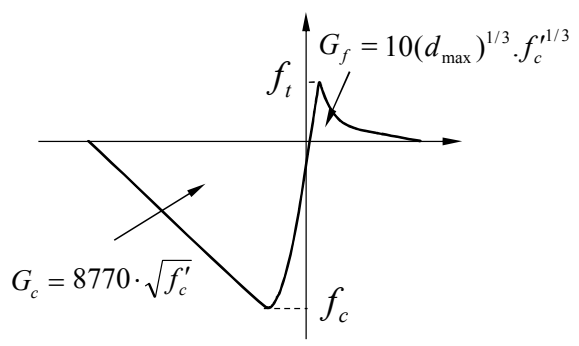

(a) Concrete

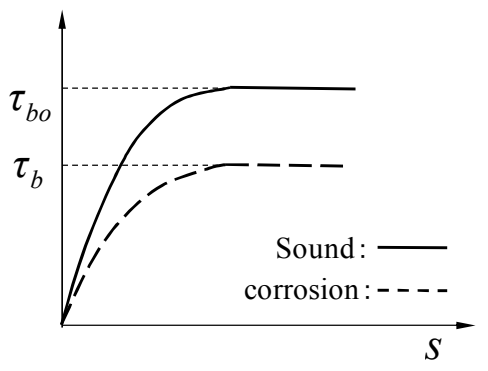

(c) Bond behavior

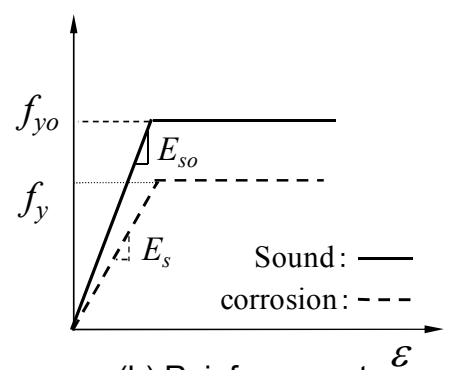

(b) Reinforcement

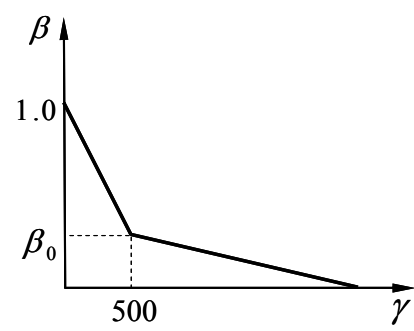

(d) Shear retention

Fig. 11 Constitutive law.

\section{(3) Shear behavior after cracking}

In concrete beam members, even after diagonal cracks occur, the shear stress can also be transferred cross the cracks due to the aggregate interlock action along the crack surface. However, the shear stiffness of cracked concrete should be reduced gradually as the crack opening progresses and shear strain $y$ increases, which is also called shear softening. For this reason, a shear retention factor $\beta$ was introduced to take into consideration this shear stiffness reduction, and the shear softening was modeled using a bilinear $\beta-\gamma$ relationship shown in Fig. 11(d). Because the shear softening is supposed to be influenced by the shear span (Tadokoro et al. 2003), a parametric study was conducted and based on its results different appropriate $\beta-\gamma$ relationships were decided for each series of specimens.

\subsection{Analytical output}

\section{(1) B (1.5)-m series}

The analytical output of the B (1.5)-m series is shown in Fig. 12. Except for the post-peak behavior, the analytical output agrees with the experimental results (see Fig. 12(a)). Judged from the brittle failure mode observed during the load test, it should be noted that the post-peak behavior described by the analytical output seemed to be more reasonable. The irrational behavior of the experiment is thought to be caused by the load-applying method. Regarding the influence of longitudinal bar corrosion, there is little change in the load-displacement relationship between sound and corroded specimens (see Fig. 12(b)), which coincides with that of experimental results. As for crack pattern at failure, the analytical output agrees with experimental results in sound specimens, but for corroded specimens, it cannot completely reproduce the crack pattern observed in the experiment.
However, the analytical output revealed that all specimens failed in the same brittle style: after a diagonal crack initiated, it propagated rapidly toward the loading point and the support as applying load increased, and consequently it penetrated the cross section and caused an abrupt decrease in load-carrying capacity.

\section{(2) B (2.6)-m series}

Figure13 shows the analytical output of the B (2.6)-m series. Except for the post-peak behavior, the analytical output coincides with the experimental results (see Fig. 13(a)). Regarding the load-displacement relationship, the corroded specimens exhibited a clear decrease in post-crack stiffness, and a significant increase in shear capacity (see Fig. 13(b)), which coincides with the experimental results. The shift of the critical diagonal crack toward the loading point in corroded specimens was also completely reproduced by the analytical output (see Fig. 13 (c)). As described in the experimental results, this is due to the buildup of tie-arch mechanism. The distribution of stress along the longitudinal bar at failure is shown in Fig. 13(d). In the sound specimen, the stress decreased linearly from mid span to the support, which implies that the tensile stress of the longitudinal bars was transferred to the concrete due to the perfect bond effect. In corroded specimens, however, the stress along the bars exhibited hardly any change within the shear span, which implies that the tensile stress of longitudinal bars could not be transferred to concrete but to the anchorage due to the deterioration of bond strength. As a result, beam mechanism weakened and the tie-arch mechanism built up. Figure 13(d) provides additional evidence towards the conclusion drawn from the experimental results that, to state here again, the corrosion of longitudinal bars may cause a transition in the load-carrying mechanism. 


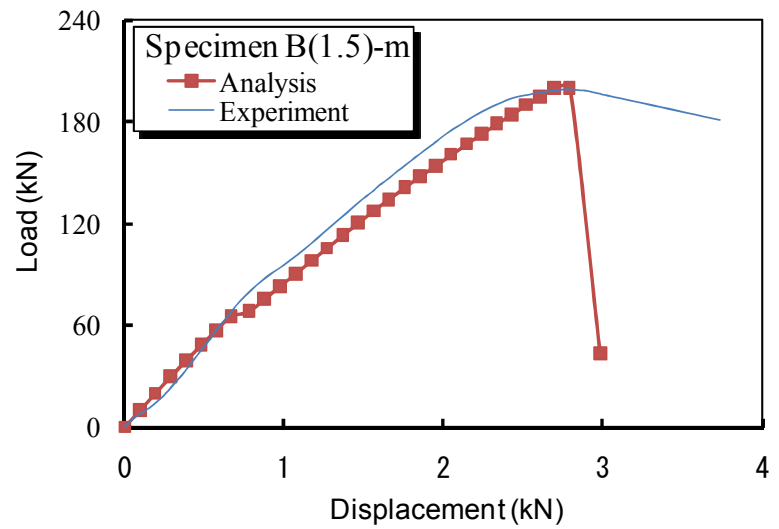

(a) Comparison of load-displacement relationship

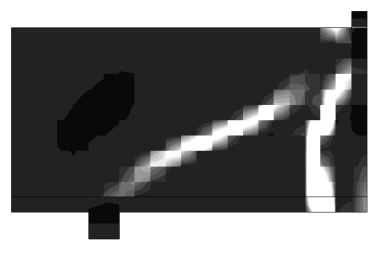

$\underline{B(1.5)-m}$

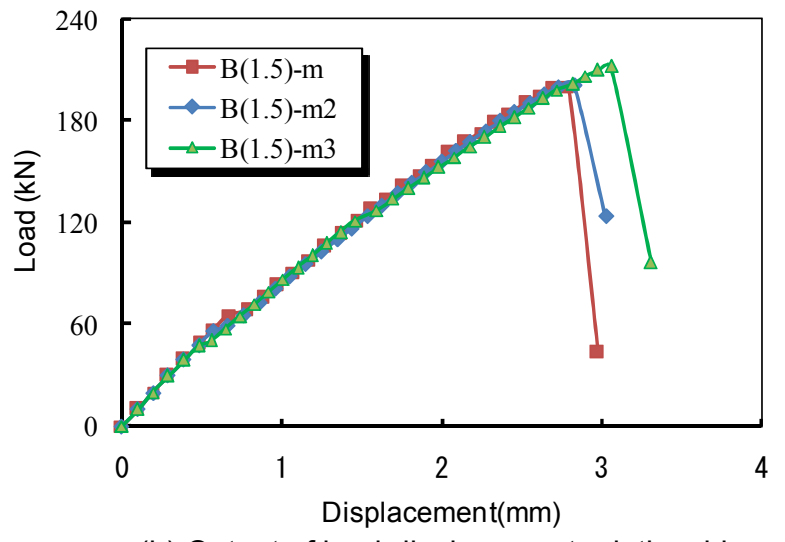

(b) Output of load-displacement relationship

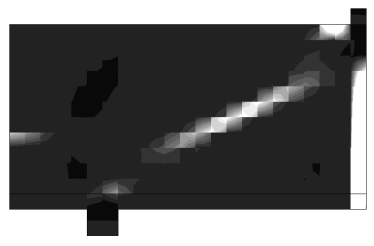

$\underline{B(1.5)-m 2}$

(c) Crack pattern

Fig.12 Analytical output of $B(1.5)-m$ series

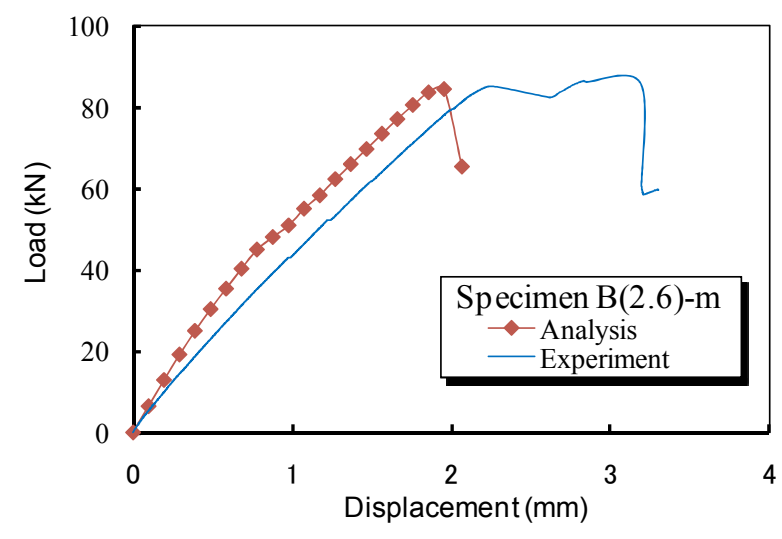

(a) Comparison of load-displacement relationship
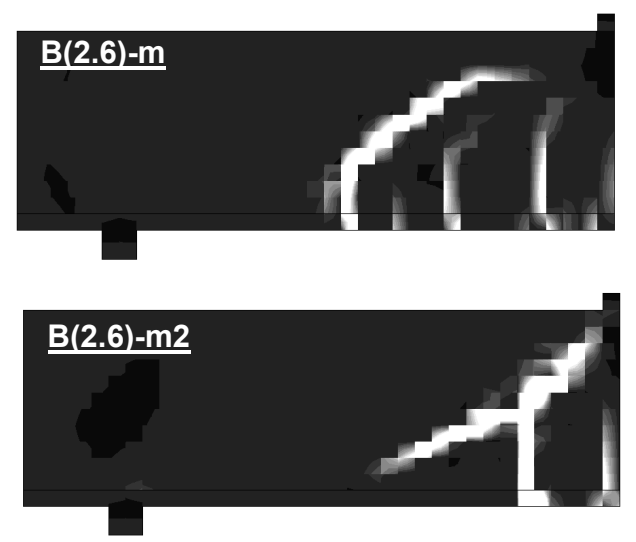

(c) Crack pattern

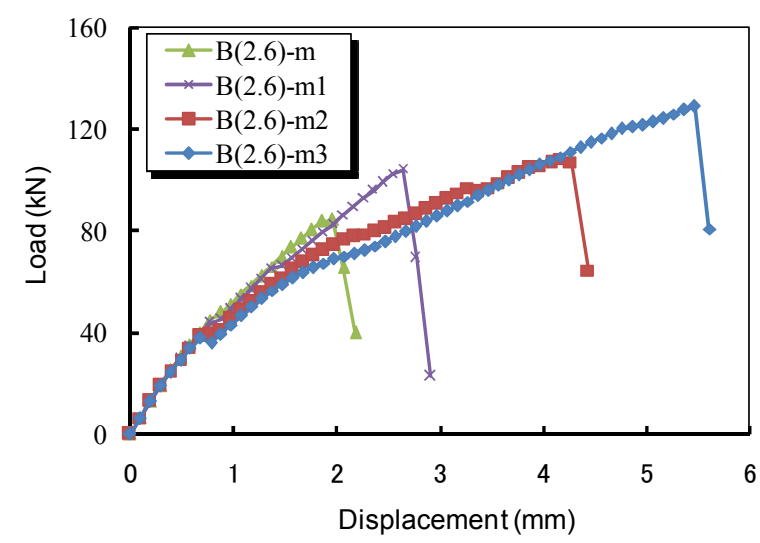

(b) Output of load-displacement relationship

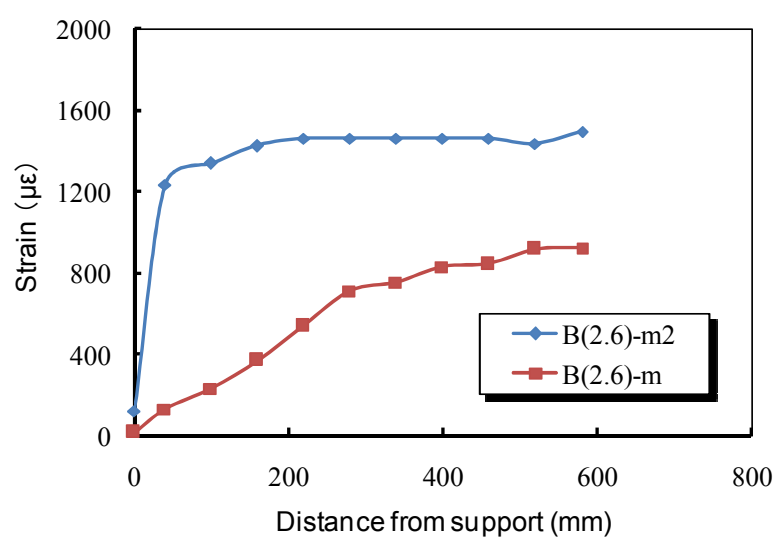

(d) Distribution of strain along longitudinal bars at ultimate

Fig.13 Analytical output of $B(2.6)-m$ series 


\section{Quantification of the influence of longi- tudinal bars corrosion}

\subsection{Evaluation of shear capacity}

Figure 14 shows the evaluation results of shear capacity for all specimens using the shear equation Eq. 2 and Eq. 3. It can be seen that the shear capacity of sound specimens were properly evaluated, which gives some validity to the experimental results. Regarding the corroded specimens, the result was an undervaluation for specimens with an a/d below 3.0, and an unsafe evaluation for specimens with an a/d above 3.0. The evaluation results indicate that the current shear equation cannot evaluate the shear capacity of these corroded beams properly. A modified equation based on the experimental results should be proposed.

\subsection{Systematic investigation on the influence on shear behavior}

The variation in shear capacity with the corrosion level is summarized in Fig. 15. The B (1.5)-m series, whose shear span was short, exhibited little or no change in shear capacity (see Fig. 15(a)). In the B (2.0)-m series and B (2.6)-m series with relatively longer shear span, shear capacity increased as the corrosion level increased (see Fig. 15(b)). The B (3.5)-m series and the B (4.0)-m series, whose shear spans were longer, however, exhibited a decrease in the shear capacity as the corrosion level increased (see Fig. 15(c)). It was obvious that the shear capacity was influenced not only by the corrosion level of the longitudinal bars, but also by the shear-span-to-effective-depth-ratio.

\subsection{Quantification of the influence of longitudi- nal bars corrosion}

Based on the experimental results, the modified equation can be proposed as:

$$
\begin{aligned}
& V_{u-\text { eval }}=\alpha_{1} \cdot V_{u} \\
& \alpha_{1}=f(a / d, C)
\end{aligned}
$$

Where $V_{u \text {-eval }}$ is the shear capacity of corroded RC beams, $V_{u}$ is the shear capacity of sound RC beams, $C$ is average mass loss of corroded longitudinal bars, $a / d$ is shear-span-to-effective-depth-ratio.

In reference to the regression function demonstrated in Fig. 15, $\alpha_{l}$ can also be expressed as:

$$
\alpha_{1}=1+k \cdot C
$$

Where $k$ can be regarded as the inclination of the regression curve depending on $a / d$.

The $k$-a/d relationship can be derived from Fig. 15, as shown in Fig. 16. From the regression function specified in Fig. 16, $k$ can be expressed as:

$$
k=0.13-0.04 \times(a / d)
$$

From Eq.9 Eq.12, the modified equation can be ex-

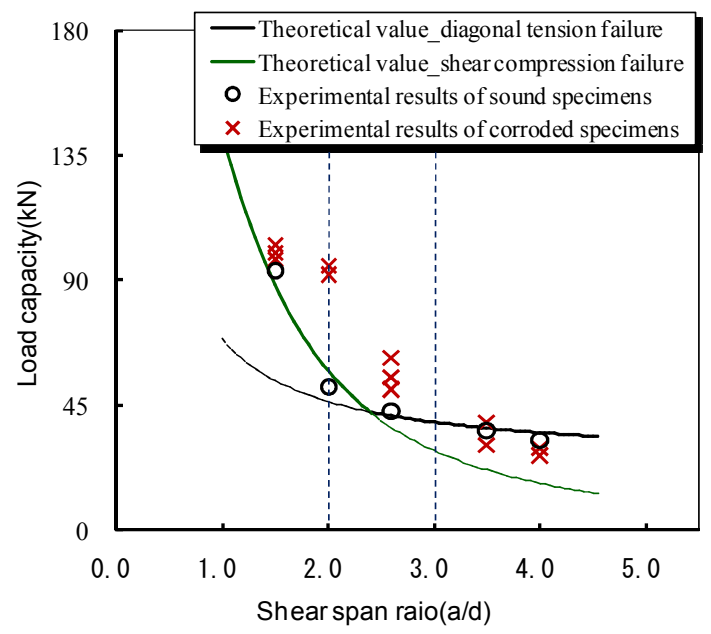

Fig.14 Evaluation of shear capacity

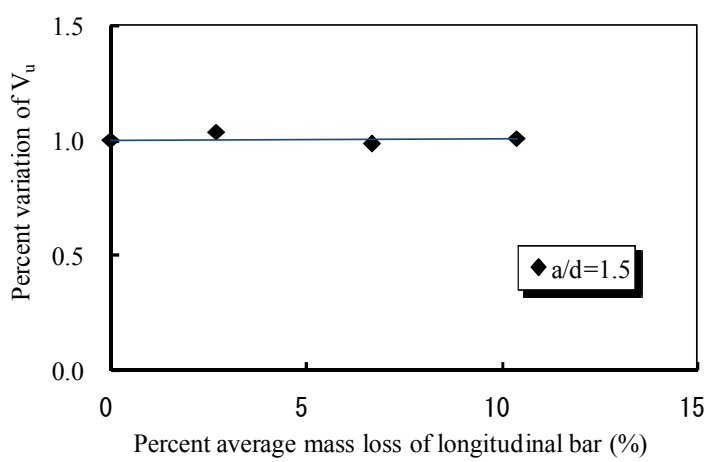

(a) Specimens with short shear span

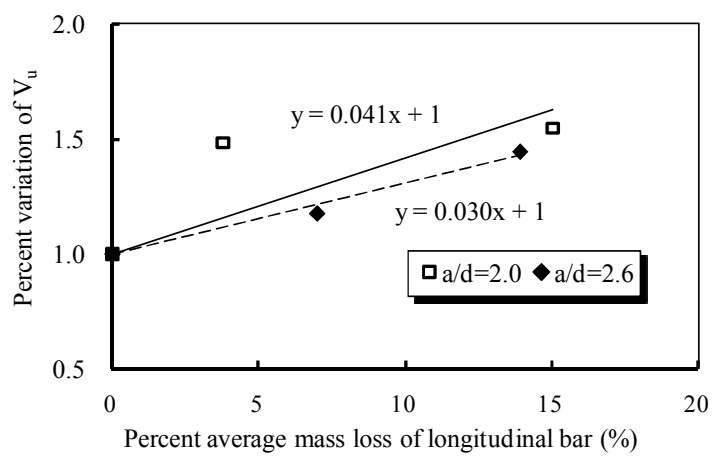

(b) Specimens with moderate shear span

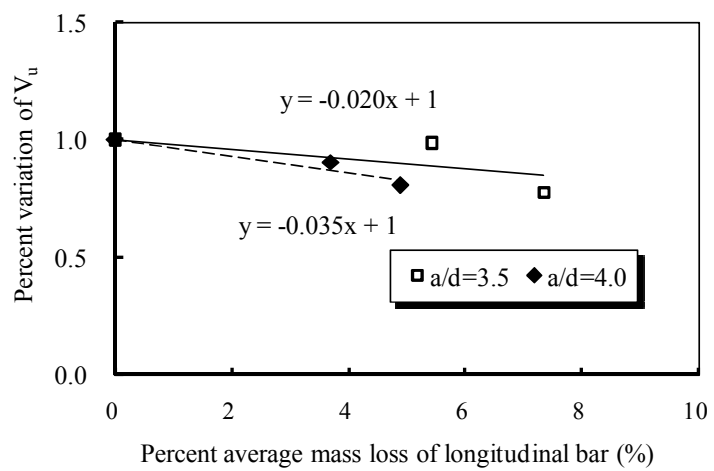

(c) Specimens with long shear span

Fig.15 Influence of longitudinal bars corrosion 
pressed as:

$$
V_{u-\text { eval }}=\{1+[0.13-0.04 \times(a / d)] \cdot C\} \cdot V_{u}
$$

Where $V_{u}$ is the shear capacity of sound specimen, which can be calculated using shear equation Eq. 2 and Eq3.

\subsection{Validity of the proposed modified equation}

The relevant experimental data of published research (Sato et al. 2003; Matsuo et al. 2004; Hashimoto et al. 2003, Inoue et al. 2004, Xue and Seki 2005) are introduced to verify the proposed equation. The scope of all the experimental data is specified as follows:

Shear-span-to-effective-depth-ratio $\quad a / d: 2.5 \sim 4.0$ Percent average mass loss of

$$
\text { longitudinal bars } \quad C_{m}: 0 \sim 18 \%
$$

The validation results are shown in Fig. 17, revealing that the proposed equation predicted reasonably well the shear capacity of all experimental data, giving a mean of $V_{\text {test }} / V_{\text {u-eval }}$ of 1.04 , with coefficient of variation of $13 \%$.

\section{Conclusion}

This paper focused on the shear behavior of $\mathrm{RC}$ beams with corroded longitudinal bars. Load tests were conducted to specimens whose longitudinal bars were subjected to accelerated corrosion tests to investigate their shear behavior. Analytical investigations were also performed to reveal the load-carrying mechanism of these specimens. From the experimental results and analytical output, the following points have been concluded:

1. The bond behavior between longitudinal bars and concrete plays a very important role in the load-carrying mechanism of RC beams. As longitudinal bars corrode, the deterioration of bond strength may reduce the stiffness of $\mathrm{RC}$ beams, and furthermore result in a transition of the load-carrying mechanism.

2. The shear behavior of RC beams with corroded longitudinal bars is influenced not only by the corrosion level of longitudinal bars, but also by the shear-span-to-effective-depth-ratio.

3. When the shear-span-to-effective-depth-ratio is above 3.0, the prediction of the shear capacity of RC beams with corroded longitudinal bars using current shear equation will result in an unsafe overvaluation

4. A modified equation based on the experimental results was proposed. A validation using all available experimental data revealed that this proposed equation generally predicts the shear capacity of RC beams with corroded longitudinal bars.

5. In this paper, the end anchorage of longitudinal bars played a very important role in shear behavior. It must be noted that the premature end anchorage failure may result in the dramatically decrease in shear capacity. Many other factors such as top longitudinal bar condition, load style (distributed load or concentrated load) may have influence on the shear behavior of RC beams with corroded rein-

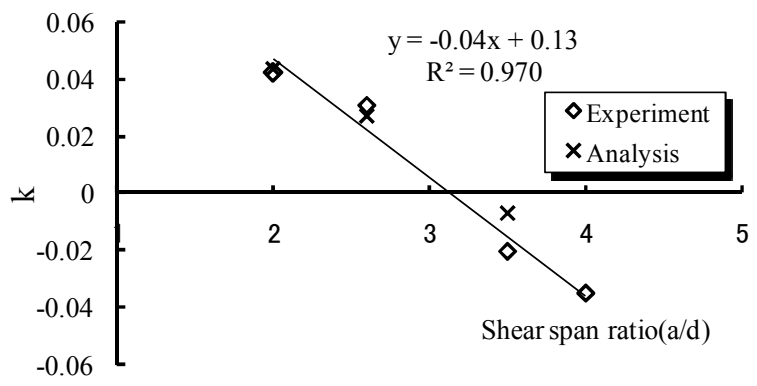

Fig.16 k-a/d relationship

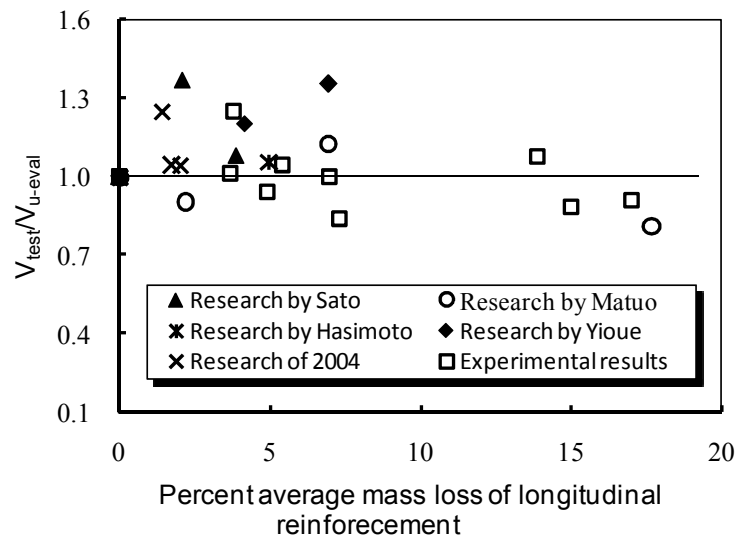

(a) $V_{\text {test }} / V_{\text {u-eval }}-C$ relationship

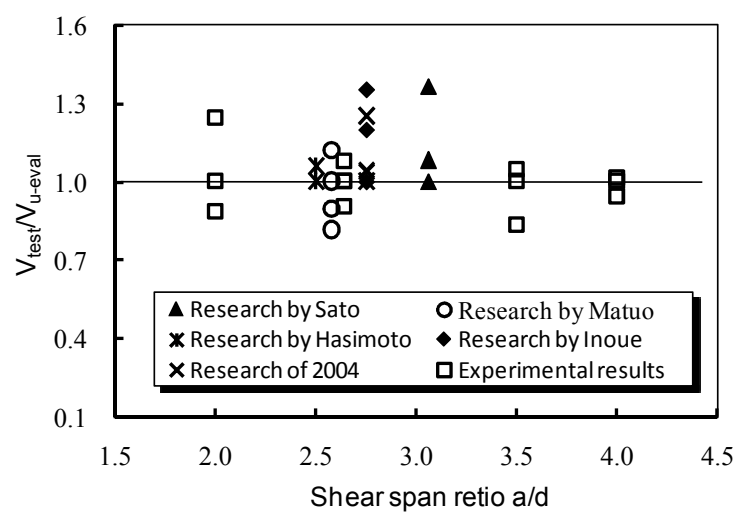

(b) $V_{\text {test }} / V_{\text {u-eval }}-a / d$ relationship

Fig.17 Validation results of proposed equation

forcement. Further study is expected to cover these parameters in the near future.

\section{Acknowledgement}

The authors would like to thank Dr. Inoue Susumu, Osaka Institute of Technology, and Dr. Yamamoto Takashi, Kyoto University, for their valuable advisor for this paper. Special thanks are also extended to TOKYO TEKKO CO., LTD. for their providing of Ultra-high strength steels.

\section{References}

Dörr, K. (1980). "Ein Beitrag zur Berechnung von Stahlbetonscheiben unter besonderer Berücksichtigung des Verbundverhaltens." Thesis 
(PhD). University of Darmstadt.

Fenwick, R. C. and Paulay, T. (1968). "Mechanisms of shear resistance of concrete beams." Journal of the Structural Division, ASCE, 94(ST10), 2235-2350.

Hashimoto, K., Morikawa, H. and Kobayasi, H. (2003). "Evaluation of shear behavior of RC beams taking into consideration of reinforcement corrosion." Proceedings of the Japan Concrete Institute, 25(2), 1009-1014. (in Japanese)

Hordijk, P. A. (1991). "Local approach to fatigue of concrete." Thesis (PhD), Delft University of Technology.

Inoue, H., Xue, X. and Seki, H. (2004). "Influence of reinforcement corrosion on shear capacity." JSCE Annual Journal of Materials, Concrete Structures and Pavements, 425-426. (in Japanese)

JSCE, (2006). "Structural performance of concrete structures with deteriorated materials-Concrete engineering series 71." Tokyo: Japan Society of Civil Engineers.

JSCE, (2007). "Standard specification for design and construction of concrete structures." Tokyo: Japan Society of Civil Engineers.

Kosa, K., Wakiyama, T., Nisioka, T. and Kobayasi, H. (2007). "Effect of shear span ratio on the fracture of deep beams." Journal of Materials, Concrete Structures and Pavement, 62(4), 798-814. (in Japanese)

Matsuo, T., Sakai, L., Matsumura, T. and Kanetsu, N. (2004). "Studies on the shear load carrying mechanism of RC beams with corroded reinforcement." Concrete Journal, 15(2), 69-77. (in Japanese)

Niwa, J. (1983). "Shear equation of deep beams based on analysis." Proceedings of JCI $2^{\text {nd }}$ colloquium on shear analysis of RC structures, 119-128. (in Japanese)

Niwa, J., Yamata, H., Yokozawa, W. and Okamura, H. (1986). "Revaluation of the equation for shear strength of reinforced concrete beams without web reinforcement." Journal of Materials, Concrete Structures and Pavement, (372), 167-176. (in Japanese)

Sahamitmongkol, R., Suwathanangkul, S., Phoothong, P. and Kato, Y. (2008). "Flexural behaviors of corroded flexural RC members with patch repair- Experiments \& simulation." Journal of Advanced Concrete Technology, 6(2), 317-336.

Sato, Y., Yamamoto, T., Hattori, A. and Miyagawa, Y. (2003). "Influence of stirrups and longitudinal bars corrosion on shear behavior of RC members." Proceedings of the Japan Concrete Institute, 25(1), 821-826. (in Japanese)

Tadokoro, D., Sato, Y. and Ueta, T. (2006). "Shear Transferring Mechanism Along Diagonal Cracks and Diagonal Tension Failure Behavior of RC Members." Journal of Materials, Concrete Structures and Pavement, (739)V-60, 195-211. (in Japanese)

Tanabe, T., Higai, T., Umehara, H. and Niwa, J. (2000). "Concrete structure." 4th ed. Tokyo: Asakura Publishing Co., Ltd. (in Japanese)

Xue, X. and Seki, H. (2005). "Influence of reinforcement corrosion on shear capacity. "JSCE Annual Journal of Materials, Concrete Structures and Pavements, 1057-1058. (in Japanese)

Yamamoto, T., Sato, Y., Hattori, A. and Miyagawa, T. (2005). "Studies on the shear behavior of RC beams with corroded reinforcement." Proceedings of the Japan Concrete Institute, 27(1), 913-918. (in Japanese) 